\title{
The Cultural Connotation and Social Function of the Yi Big Sanxian Dance
}

\author{
Yaping Qiu ${ }^{1, a}$ \\ ${ }^{1}$ Department of dance, School of Arts, Yunnan University of Nationalities, 650500 \\ ${ }^{a}$ email
}

Key words: Yi big Sanxian dance; big Sanxian; intangible cultural heritage; Heritage

\begin{abstract}
The national dance is an important part of the national culture, the Yi dance was born in the Yi People's ancestors, the accumulation of experience in the production process. Yi of the big Sanxian dance is a typical dance of the Yi ethnic dance. In recent years, the Yi big Sanxian dance become one of the intangible cultural heritage items, the role in Yi dance from the plucked string instrument Sanxian cut, the national characteristics of the research on the Yi big Sanxian dance, and dig the cultural connotation of the Yi big Sanxian dance, respectively on the Yi big Sanxian dance culture inheritance, popularization and integration of theThe interpretation of focus from the aspects of social significance and popularization and heritage, summarizes the social value of the big Sanxian Yi dance.
\end{abstract}

\section{Plucked Instrument Three-Stringed Instrument in the Role of the Yi People's Dance}

Yi dance accompaniment, musical instruments small Sanxian earlier, use usually men while playing edge dance, women's edge dance edge hand beat double pedal to collaboration, "trichord is Yi singing and dancing of holiday celebrations, rites and ceremonies and other important accompaniment musical instruments" [1], in the twenties of the eighteenth century, the Yi people think general Sanxian musical instruments can not meet the detailed expresses young people's emotions and transformation of the big Sanxian. Sanxian is used in the song and dance of the Yi people of the most common instruments, in the ritual dance, dance festival, celebration, song and dance of the Yi people often have three stringed accompaniment, Yi the Sanxian is divided into large, medium and small types, is Chinese folk musical instruments are relatively rare in the bass "[2]. Trichord voice, loud, plays an important role in Yi dance. "Trichord enrich the content of Yi dance accompaniment, let Yi dance accompaniment rhythm playing Sanxian musical accompaniment of the special symbol" [2]. Three - stringed instrument in the hands of players, through the left and right in coordinated operation. Playing a dance to the rhythm of music, is a form of dance of Yi nationality is one of the most important accompaniment. Yi trichord is Yi, dance accompaniment in most of the national characteristics of the instruments, is the Yi native instruments, Yi and other ethnic groups to distinguish between an important symbol of the accompaniment of music. Yi three stringed instruments are different, in solo and group dance plays a important role, a three stringed accompaniment is essential in Yi holiday dance.

\section{The Characteristics of the Yi People's Large Three-Stringed Dance}

Yi nationality is a nation with a long history and cultural traditions, it is a good national dance, the yi people's dance originated in the process of production and life of the yi people's ancestors. "Is often associated with holiday, sacrificial ceremony, has been developed continuously in the historical process, become the yi a way of expressing emotions" [3]. Yi large three-stringed dance classes have a lot of kinds, 
suitable for people of different ages, yi three-stringed dance jump method is usually carried out in accordance with the $5 / 4$ clap, per section 5 , three steps starting from the left to jump to the left, then raised his right leg, hook foot pedal down twice, once a clap, clap your hands twice at the same time; Then turn to the right three leaps, and then raised his left leg, hook foot pedal down twice, one at a time, to clap hands twice at the same time, by analogy, repeated cycle. Yi large three-stringed dance for a group of people dance together, fast, long, people dance and sing, under the influence of music atmosphere, WuRen mood is easy to mobilize refs.

In the traditional festival, native people gather together and celebrate a festival in the form of singing and dancing, distribution in different parts of the yi nationality, there are different forms of dance, among them, the qujing city the drought-hit luliang county yi large three-stringed dance, and people are more distinctive dance in the dance of the yi nationality. From yi can research at the time of history, large three-stringed dance has become the region people celebrate holidays and labor group dance of the harvest. Originating from the production and living, perfecting changes, dance form is: yi ku up three-stringed play while dancing, young man, overnight, in the form of singing and dancing and harvest celebrations. Yi large three-stringed dance is not formalized, time and space, by parents inheritance children inheritance in yi, yi is large three-stringed dance performance yis collective dance of the happy mood in the process of production and life.

Yi large three-stringed dance dance basic form three steps for men and women a kicking, female dancers will turn 360 degrees, after three steps queue is strewn at random have send. Yi people's enthusiasm is bold and unrestrained dance, rapid and theres is no lack. Presentation to attend in their holiday best, and a combination of dance, play, blowing, sing four style of acting. For large three-stringed dance to yi yi culture, is a kind of important form to show the yi culture.

\section{Cultural Connotations of the Yi People's Large Three-Stringed Dance}

A folk dance, and national historical and cultural background, the ecological environment has a great influence, this kind of art form, dance is created by the people in the production and living art sublimation, is the important of human spiritual civilization. Yi large three-stringed dance is a form of outstanding representatives of the yi people's dance, dancing is an important part of the yi ethnic culture, inheriting elutriation process over time. In the dance of the yi nationality different dance content can appear in different yi celebration occasions. In history, yi large three-stringed dance contains the yi ethnic cultural heritage and against nature, the yi people's ancestors happy wisdom of farming. Yi dance culture by yi large three-stringed dance to inherit, popularization and reproducible. In recent years, yi large three-stringed dance become appeared in the spread of the audience in front of a form of dance, higher frequency and become the national non-material cultural heritage, full attention, yi large three-stringed dance to further reveal the cultural connotation, through the form of dance and dance content, can from deeper level mining yi ethnic cultural heritage.

Time is can't prove that yi dance, but yi dance inheritance continuously in the long time development. Yi dance molding in yi's ancestors in the accumulation of experience in the process of production and living. In yi nationality dance, three string expression derived from the production experience in production and living, the yi people's ancestors yi ancestors for a long time history, has been taking process as the main way of life, according to legend, during the slavery period, area, the yi people's ancestors in order to let the slave to speed up work, slave owners more than with the method of burning plant, the yi people's ancestors, must immediately after the fire work, to step on your feet after the land after the fire burning, in order to make his own feet as little damage as possible, while jumping the yi 
people's ancestors work, the most primitive form of yi nationality dance began to emerge. Then, in the form of dance moves joined the kicking action and upper limbs with sports, become a more long yi's history, heritage area is relatively wide dance - "fine TiaoYue o", "big and three-stringed dance". Yi dance from the origin to the development and production activities of the yi people's ancestors have inseparable relationship, contains the ethnic culture of the yi nationality, in the dance of the inheritance of the yi people's dance with the yi has a lot to do with similar production way of life.

Yi dance has a strong national characteristics, the yi love of dance derived from blood, born with. Everybody hear flute three-stringed ring, foot pole will itch ". Yi's "big three" rich strong appeal. Every important holiday or festival activities, the yi singing and dancing, to celebrate. Dance in yi's popularity is very big, with the sound of mode of transmission, through TV, Internet and other media carrier, the scope of the spread of the yi people's dance more and more widely, more and more people who love to dance to contact yi dance, yi large three-stringed dance, for old and old people and young people to participate in. "Fine TiaoYue o" and "and large three-stringed dance" participants mainly for the youth, the two yi branches, different content of the same form of dance, yi youth to the pursuit of marriage as the main goal. The former is developed in the original, which is gradually formed in the daily demand, living in different parts of the form of traditional dance of the yi people's two. In city, yi, yi large three-stringed dance lesson hold was placed on the school, from the students, to promote and inheritance of the yi people's dance. In addition, the yi people's dance in the spread of various nationalities, reality yi large three-stringed dance culture popularization and the fusion of the yi people's culture and Chinese culture.

Yi large three-stringed dance rhythm and showing the enthusiasm for the more and more people, can bring people the beautiful feeling. Yi large three-stringed dance was due to political, social, imprisoned for ten years, ten years later, yi large three-stringed dance a blooming vitality, on the torch festival of the yi people's biggest appeared again, and quickly back to the audience. On the basis of yi large three-stringed dance, made into a square dance of popular spread all over China, spread of the yi people's dance embodies the national integration and cultural development in our country social scene. Yi more and more large three-stringed dance audience by yi large three-stringed dance, more and more people learned the ethnic dance form and spirit. The spread of yi large three-stringed dance, is a loud to carry forward yi culture famous brand. Dance performers through to the yi big three-stringed dance learning, understanding, and the national spirit of yi ethnic style. Yi large three-stringed dance become a kind of general dance. Yi large three-stringed dance and modern popular square dance mutual complement each other, USES the method of yi large three-stringed dance performances, rich forms of yi the three-stringed dance show.

\section{Yi three-stringed dance of social values}

$\mathrm{Yi}$ is a nation with a long history and civilization, have their own native language, a lot of precious national culture gets to be popularized in the form of text, yi large three-stringed dance has a long history, dance form and content from yi ancestors refining, the processing of production, living, is a living fossil of the yi people's cultural heritage, at present, yi large three-stringed dance heritage, is an important heritage of yi traditional culture. On the one hand, yi large three-stringed dance is an important part in Chinese traditional culture, is an effective way to promote and spread the Chinese culture. Yi large three-stringed dance, on the other hand, the reaction is yi this nation's aesthetic taste, is layer upon layer of accumulation of national culture. Yi large three-stringed dance of recreational, thoughtful, emotional and artistic, is to understand an important point of traditional Chinese culture. 
Yi large three-stringed dance, make the yi culture diffusion, through the form of dance, China and even all over the world people can dance in the form of access to the yi nationality culture, promoted the social influence of yi culture, let to yi yi culture as an opportunity to dance with the possibility of widespread. Yi nationality dance, in the form of art, shows the yi ethnic character, expanded yi world fame, let yi ethnic style are shown.

Yi large three-stringed dance has become in the dance of the yi nationality can represent important characteristic of yi nationality dance dance forms, convey the thought of yi people's enthusiasm, frank, straightforward national personality. Dance for the yi nationality, has the special significance, it is not only a kind of art, is also in the recreational activities of daily life of the people, dance originated in the sublimation of People's Daily life and production, the same as the other ethnic groups, the yi in his important festivals, harvest, will be in the form of dance in the rain to celebrate and to express their respect to the gods and ancestors. The form of dance and movement after one thousand years of tradition, which contains the rich national cultural essence.

On June 14, 2008, yi large three-stringed dance known as one of the state council announced the second batch of intangible cultural heritage, yi large three-stringed dance history, cultural significance of national important attention has been given to, heritage and development of the yi people's large three-stringed dance began from the folk inheritance to a national inheritance. "With the development of the yi area tourism economy, some settlements in yi yi large three-stringed dance performances such as performance, to welcome let yi big three-stringed dance become a important project of the yi people's residence tourism" [18]. Yi large three-stringed dance, can make into visitors expressed the real feelings of the yi people's dance of the yi people's live essence of national culture.

\section{Conclusion}

Yi region three stringed instrument is different with other areas, three stringed instrument yi, except for playing on the shape and structure is different from other ordinary three stringed instruments, bold loud and clear voice, appearance looks sophisticated chic, playing at the same time convenient dancers dancing. Yi three stringed instrument played, it's easy to create a warm, happy, bold and unrestrained music atmosphere. Yi people's worship of fire, from yi large three-stringed dance, can feel the yi is very distinctive national character. Yi large three-stringed dance contains rich cultural connotation of yi, yi ancestors is engaged in the production, the life of a lot of experience, through the form of dance. Yi large three-stringed dance general sexually transmitted, enlarged the influence of yi culture, let more people understand the yi ethnic culture.

\section{References}

[1] XieJun. Fine TiaoYue and and large three-stringed dance (the)-two yi branches, music, dance, and comparative study of cultural context [J]. Journal of central music college, 2008, (1): 89-90.

[2] Mr. Ethnic music yunnan ethnic Musical Instruments is introduced Shilin yi and folk musical instrument [J]. Journal of national music, 2014, (1): 2-3.

[3] Huang Pingshan BiGuangYun. Yi large three-stringed instrument [J]. Journal of China national, 2007, (4): 4-7. 